\title{
Derivation of Path of Contact and Tooth Flank Modification by Minimizing Transmission Error on Face Gear*
}

\author{
Tetsuo INOUE** and Syuhei KUROKAWA*** \\ ** Department of Reel Development, Shimano Inc., \\ 3-77 Oimatsu-cho, Sakai-ku, Sakai-shi, Osaka 590-8577, Japan \\ E-mail: inotet@sic.shimano.co.jp \\ *** Department of Mechanical Engineering, Kyushu University, \\ 744 Motooka, Nishi-ku, Fukuoka-shi, Fukuoka 819-0395, Japan
}

\begin{abstract}
This research report discusses how to derive a path of contact on a face gear. A sample was manufactured, in which tooth modification is taken into account, and the sample was investigated as to whether it is robust against alignment errors. It has been verified that the assembly operation can be improved in mass production line.
\end{abstract}

Key words: Face Gear, Path of Contact, Tooth Flank Modification, Transmission Error, Fishing Reel

\section{Introduction}

Face gear is commonly used in fishing spinning reel mechanisms (Figure 1) because it is easy to be formed and because of the good rotational feeling it offers. Especially face gear has no undercut therefore it can be mass-produced by cold forging or die casting at a low cost. It is however very sensitive to alignment errors. Moreover, the demand for the good level of rotational feeling has been increasing year by year. Therefore, the time required for adjustment during the assembling of a reel has been increasing.

On the other hand, there have been some research reports on hypoid gear substitution for a face gear. One of these face gears has been adopted in a transmission system of a helicopter ${ }^{(1)}$. Although there have been many researches on tooth design method ${ }^{(2)-(5)}$ and manufacturing method ${ }^{(6)-(7)}$, there is only a few researches on tooth modification method $^{(8)(9)}$. This report discusses how to derive a path of contact on a face gear according to the minimization of transmission errors. The tooth flank was optimized based on the path and manufactured. Robustness against alignment errors was inspected and rotational feeling was verified through the assembling of a fishing reel.

\section{Alignment Error}

Table 1 shows dimensions of a face gear used in this research. A 3D tooth model of the face gear was created with the specification and shown in Fig.2. The face gear has a conjugate relationship with the pinion gear.

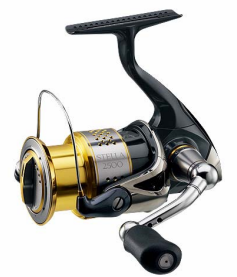

Fig 1 Spinning reel

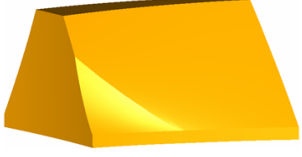

Fig 2 3D tooth model
Table 1 Dimensions of face gear pair

\begin{tabular}{cc||c|c}
\hline \hline \multicolumn{1}{c||}{} & Pinion gear & Face gear \\
\hline Normal module & $\mathrm{mm}$ & 0.65 & 0.65 \\
Pressure angle & deg & $20^{\circ}$ & $20^{\circ}$ \\
Number of teeth & & 6 & 31 \\
Prof. shift coef. & & 0.5 & -0.5 \\
Helix angle & deg & $55^{\circ}$ & $55^{\circ}$ \\
Outer diameter & $\mathrm{mm}$ & $\phi 8.879$ & $\phi 25$. \\
Inner diameter & $\mathrm{mm}$ & $\phi 5.694$ & $\phi 21.4$ \\
Offset & $\mathrm{mm}$ & - & 6.5 \\
\hline \hline
\end{tabular}


The reference position is defined at where the pinion gear and the face gear are in contact at the pitch circle. Fig. 3 illustrates the defined coordinate axes. It is known from past experience that when a height position of the pinion gear changes, the rotational feeling also changes. The influence of height errors on transmission error (TE) was investigated first.

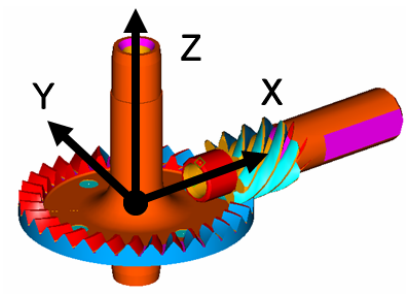

Fig 3 Definition of coordinate axes

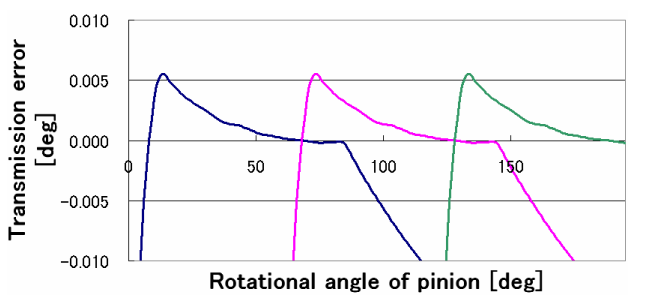

(b) $+\triangle$ contact

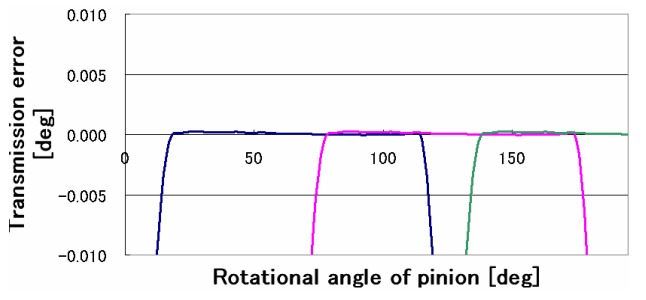

(a) Without alignment error

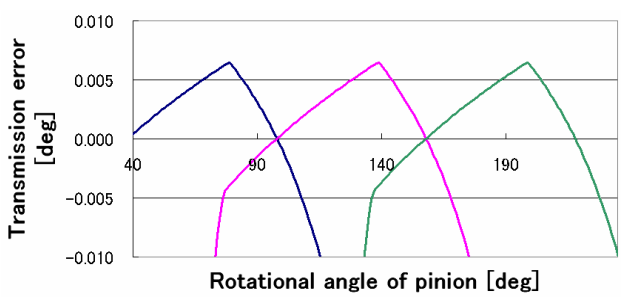

(c) $-\Delta$ contact

Fig 4 Transmission error

Fig.4 shows transmission error calculated at three types of positions on a concave side of the tooth, which is the driving side, during reel rotation. Fig.4 (a) was calculated in contact at the pitch circle without alignment error. Fig.4 (b) was calculated at the position where the pinion gear moved slight distance in the direction of $+Z$ and it is called $+\Delta$. Fig.4 (c) was calculated at the position where the pinion gear moved slight distance in the direction of $-Z$ and it is called $-\Delta$. The $\mathrm{X}$ axis represents rotational angle of pinion and the $\mathrm{Y}$ axis represents TE. Each curve was calculated only for one tooth and those for the preceding and succeeding teeth were shifted by one pitch of the face gear. The calculated result illustrates that, when the height position of the pinion gear changes, transmission error changes drastically.

\section{Definition and Derivation of Path of Contact}

\subsection{Meshing condition diagram}

Fig. 5 is meshing condition diagram, and viewing direction of the tooth flank is indicated by the arrow in Fig.6. The meshing condition diagram represents a path of contact points along a concave flank. The $\mathrm{X}$ axis represents radius of face gear and the $\mathrm{Y}$ axis represents tooth height. Angles in the diagram represent rotational angles of the pinion, whose TE corresponds to that shown in Fig.4 (b) and (c).

In the case of the $-\Delta$ contact, the contact point moves along the outside edge and the edge of the tooth tip. In the case of the $+\Delta$ contact, the contact point moves along the root interference edge and the inside edge. In Fig.4 (b), the peak position of the second tooth corresponds to the point of $74^{\circ}$ on the $+\Delta$ contact path in Fig.5. In Fig.4 (c), the peak position of the second tooth corresponds to the point of $139^{\circ}$ on the $-\Delta$ contact path in Fig.5. Based on this result, it is regarded that TE is dependent on tooth flank shape. 


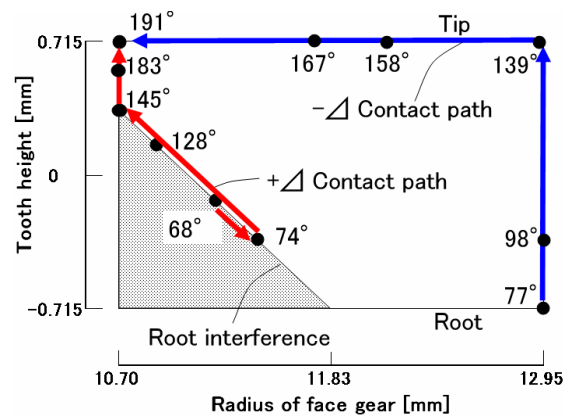

Fig 5 Meshing condition diagram

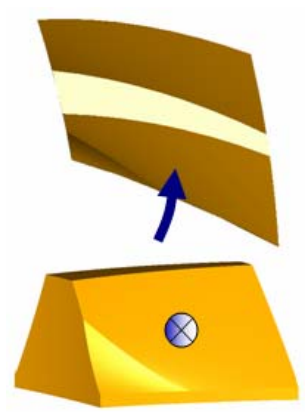

Fig 6 Viewing direction

If the TE curve of - $\Delta$ contact changes into the flat curve as shown in Fig.7, it can be inferred that the gear pair meshes without TE. This situation is regarded as an optimum. The path of contact in the optimum situation needs to be obtained. Fig. 8 shows some curves predicted on the face gear tooth flank.

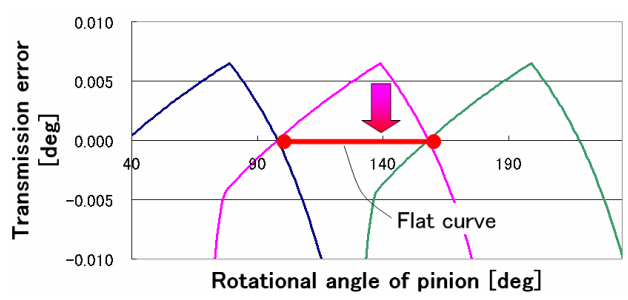

Fig 7 TE curve of $-\Delta$ contact meshing

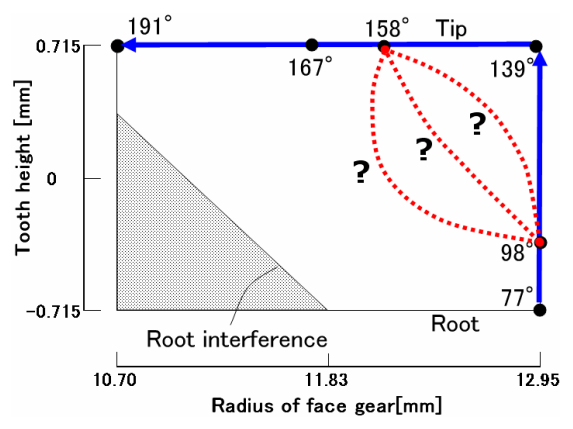

Fig 8 Meshing condition diagram of $-\Delta$

\subsection{Optimization of the path by minimizing TE}

Fig.9 shows the illustration of TE of - $\Delta$ contact. Point $\mathrm{A}$ is TE intersection of the No.1 tooth and the No.2 tooth. The point B is the peak point on the No.2 tooth. The point $\mathrm{C}$ is TE intersection of the No.2 tooth and the No.3 tooth. The point D is the intersection of the line $\mathrm{AC}$ and a line perpendicular to the line $\mathrm{AC}$ through point $\mathrm{B}$. The points $\mathrm{A}, \mathrm{B}, \mathrm{C}$, and $\mathrm{D}$ in Fig.9 correspond to those shown in Fig.10. Fig.10 is the same as Fig.5 except that contact lines are added onto this graph. It is inferred that the point D is on contact line B.

At first, the face gear and the pinion gear are positioned at an angle of $139^{\circ}$ on the contact line B. Next, only the face gear is rotated by $0.0064^{\circ}$ clockwise. Tooth surfaces overlap and the edge of the overlapped area at that time is represented as point $\mathrm{D}$. As a result, the point $\mathrm{D}$ was found using this technique.

Then the rotational angle of the face gear is calculated by subtracting TE at $139^{\circ}$ from that at $158^{\circ}$ as shown in Fig.9. Moreover TE is calculated between A and B and between B and $\mathrm{C}$, and the line ADC is derived by minimizing TE fluctuation on a $3 \mathrm{D}$ model.

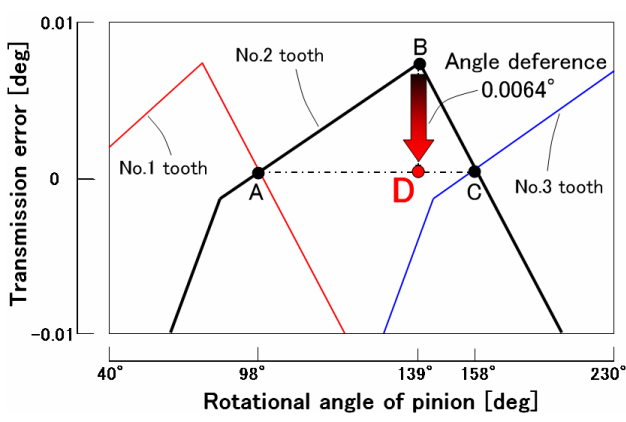

Fig 9 Illustration of TE curve

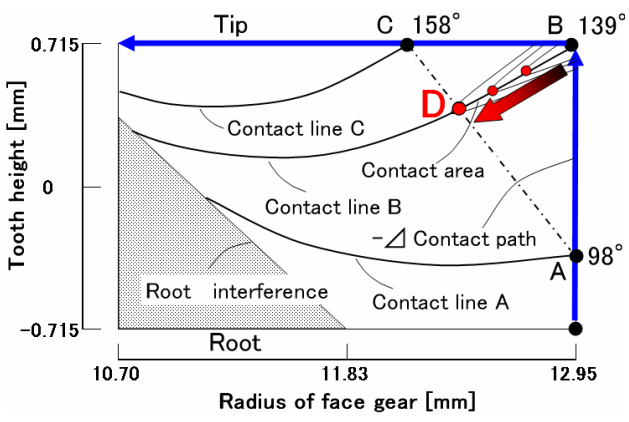

Fig 10 Meshing condition diagram of $-\Delta$ 
In order to confirm the result, the tooth on the 3D model was cut along the line ADC and TE was calculated under same condition as that of Fig.4 (c). Fig.11 shows the calculated TE with the cut tooth, and Fig. 12 shows a 3D cut tooth model. It was confirmed that fluctuation of TE was improved.

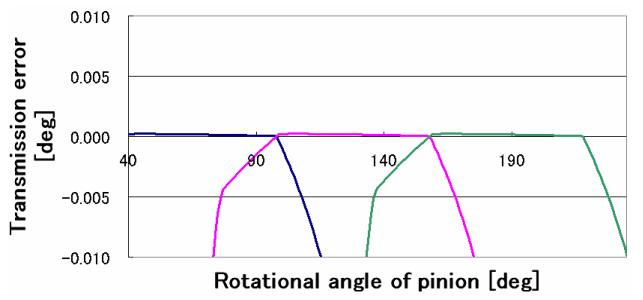

Fig 11 Transmission error of cut tooth model

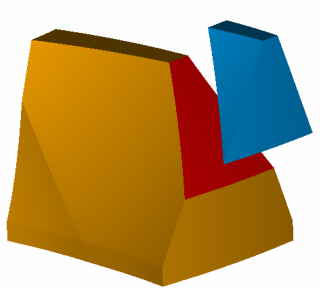

Fig 12 3D cut tooth model

\subsection{Path of contact convergence to the middle of face width}

This method was applied to $+\Delta$ contact and the curve was derived along the inner edge on face gear. The curve ab shown in Fig. 13 represents the minimized path of contact. When the rotational angle of the face gear is increased gradually, the curve ab and curve AB move towards the middle of face width. Finally, both curves converge on the same curve. Fig. 14 shows the converged path of contact on a 3D tooth model. Fig.15 shows the process of deriving a curve by minimizing transmission error. The curve ab (or $\mathrm{AB}$ ) represents the derived curve by this optimized method. And this curve moves to the curve a'b' (or A'B') with the increase of rotational angle of the face gear. As a result, no fluctuation of TE occurs, as shown in the figure. Consequently this converged curve is regarded as the optimized path of contact.

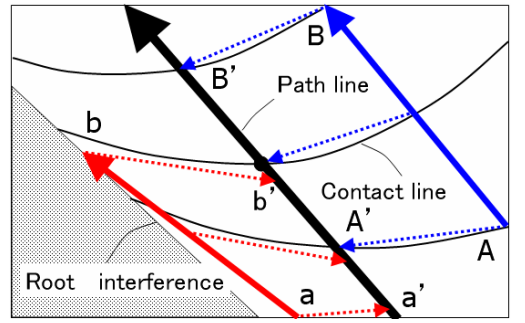

Fig 13 Optimized path of contact

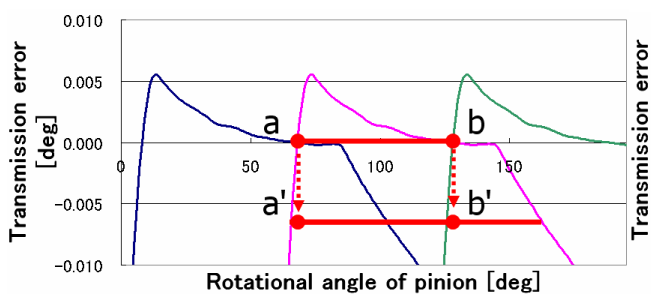

(a) TE of $+\triangle$ contact

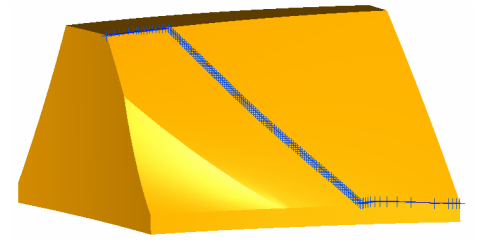

Fig 14 Path of contact on 3D model

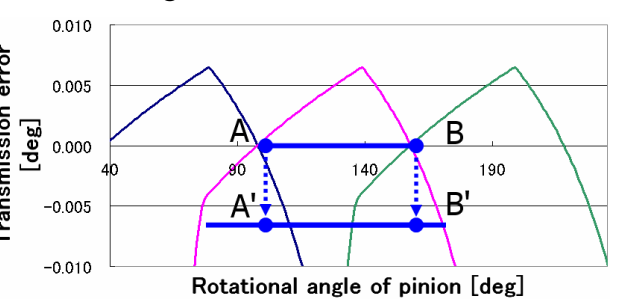

(b) TE of $-\triangle$ contact

Fig 15 Converge to the middle of face width

\section{Evaluation of Alignment Error by simulation}

In order to test the robustness against alignment errors, two types of $3 \mathrm{D}$ tooth models were prepared. One is a theoretical tooth model, referred to as conventional model. The other is an optimized tooth model, referred to as optimized model. In the case of optimized tooth model, only the tooth flank along the optimized path of contact has remained, while both sides thereof were removed from the theoretical tooth.

Fig.16 illustrates directions of alignment errors. Table 2 shows the design of experiment. TE was calculated with reference to a L9 orthogonal array, in which three noise factors are each divided into three levels. The experiment was carried out by simulation. 


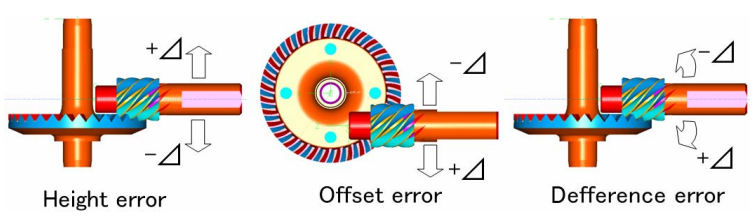

Fig 16 Direction of alignment errors
Table 2 Design of experiment

\begin{tabular}{c||c|c|c}
\hline \hline Factor name & Level 1 & Level 2 & Level 3 \\
\hline Height error & $-\boldsymbol{\Delta}$ & 0 & $+\boldsymbol{\Delta}$ \\
\hline Offset error & $-\boldsymbol{\Delta}$ & 0 & $+\boldsymbol{\Delta}$ \\
\hline Deference error & $-\boldsymbol{\Delta}$ & 0 & $+\boldsymbol{\Delta}$ \\
\hline \hline
\end{tabular}

Fig.17 shows calculated results with different alignment parameters. This graph represents the factorial effects. The $\mathrm{Y}$ axis represents $\mathrm{TE}$ and the $\mathrm{X}$ axis represents alignment errors and noise factors. The conventional model is strongly affected by the alignment error, while the optimized model is robust against the alignment error.

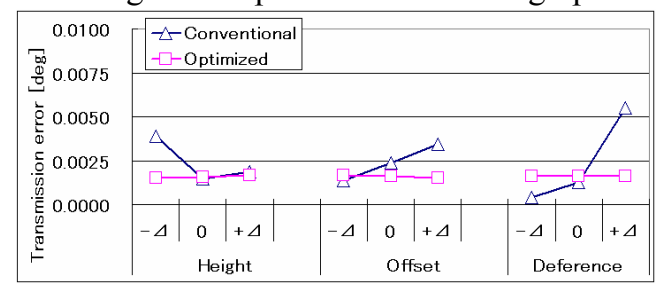

Fig 17 Response graph by 3D simulation

\section{Manufacture of the samples}

In order to confirm effectiveness of the model in practical sample, sample face gears were manufactured by a machining center using a small radius cutting tool. The sample face gears were the same used for evaluation of the conventional and optimized models. Fig.18 shows the manufactured samples.

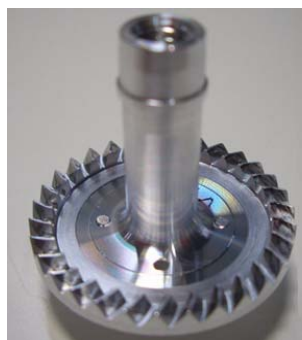

(a) Optimized

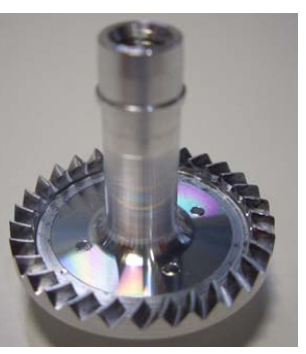

(b) Conventional

Fig 18 Manufactured Cutting

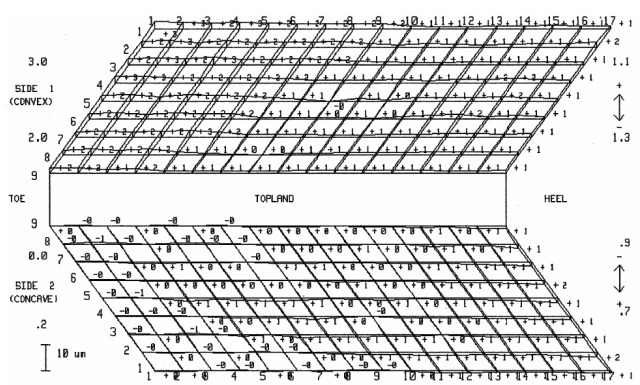

Fig 19 Result of 3D measurement

In order to confirm accuracy of cutting, both samples were measured by a 3D measurement system. Fig.19 shows the result of 3D measurement of No.1 tooth of the conventional model. For each side of a tooth, the measurement points include 153 points distributed among 9 lines and 17 columns per a tooth. In the case of this graph, maximum error of a driving tooth is $2 \mu \mathrm{m}$. It was confirmed that these samples were manufactured in high accuracy.

The tooth accuracy was measured by another measurement method. The measurements were taken along the path of contact curve from root to tip as shown in Fig.20. The measured curve consists of 92 points and the sampling interval was determined based on the regular interval of the rotational angle of pinion.

Fig.21 shows TE of the conventional model which was measured by a 3D measurement system. The $\mathrm{Y}$ axis represents $\mathrm{TE}$ and the $\mathrm{X}$ axis represents rotational angle of pinion. And this No. 2 tooth curve is the averaged curve of 4 teeth in the $90^{\circ}$ span and those for the preceding and succeeding teeth were shifted by one pitch of the face gear. From this result, $\mathrm{P}-\mathrm{V}$ value of TE was $0.0038^{\circ}$ which corresponds to only $0.78 \mu \mathrm{m}$. 


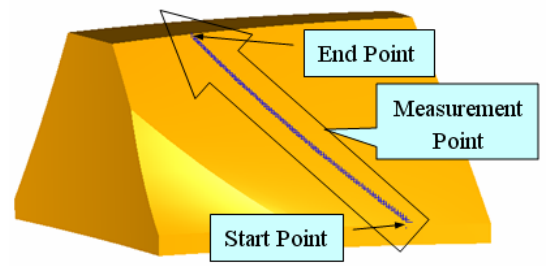

Fig 20 Measurement point on face gear

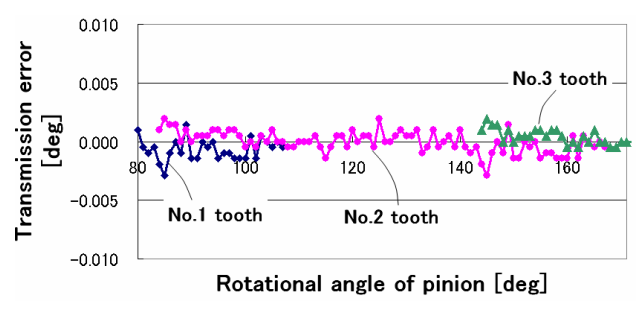

Fig 21 TE by 3D measurement system

\section{Evaluation of Alignment Error by TE measurement system}

The pinion gear used for TE measurement was measured by a gear measurement machine and it was confirmed that the pinion gear is in new JIS 3 grade. Figs 22 and 23 show results of the measurements. In these graphs, the left tooth represents a driving tooth and measured error is magnified by 2000 times.

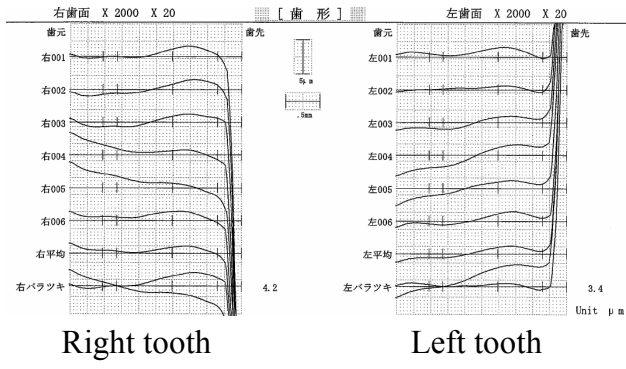

Fig 22 Result of tooth profile measurement

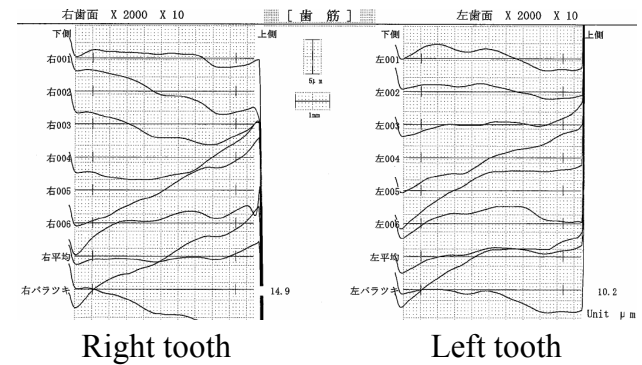

Fig 23 Result of tooth helix profile

Both samples were measured by the TE measurement system. The system has a rotary encoder of 1,296,000PPR in the driving and the driven sides. In this measurement, pinion gear was set in the driving side, and face gear was set in the driven side. Then TE of face gear was measured with reference to same conditions as shown in Table 2.

Fig.24 shows result of TE measurement. This graph represents the factorial effects. In this graph, $\mathrm{Y}$ axis represents a $\mathrm{P}-\mathrm{V}$ values in one pitch, averaged among all teeth. The TE was calculated by the following formula.

$$
\begin{aligned}
T E_{y}= & \max _{1 \leqq i \leqq n}\left\{\frac{\sum_{j=1}^{z} T E_{i j}}{\mathrm{z}}\right\}-\min _{1 \leqq i \leqq n}\left\{\frac{\sum_{j=1}^{z} T E_{i j}}{\mathrm{z}}\right\} \\
& \mathrm{n} \quad: \text { The number of the measurement points per tooth } \\
& \mathrm{z} \quad: \text { The number of teeth } \\
& \text { TE }: \text { Measured data }
\end{aligned}
$$

The conventional model is strongly affected by the alignment error, while the optimized model is robust against the alignment error similar to the result of the calculation by simulation. Differences between conventional and optimized models can be seen as absolute values, but the trends to the factor levels are almost the same as in Fig.17 and Fig.24.

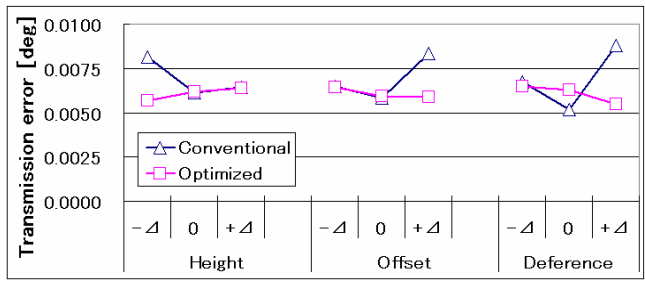

Fig 24 Response graph by TE 


\section{Measured Result of Validation in Practical Spinning Reel}

\subsection{Result of rating judgment}

To confirm the robustness of the model in practical products, sample face gears were assembled in a spinning reel. A clearance of handle axis was adjusted with a $0.05 \mathrm{~mm}$ pitch by a metal spacer from $0.02 \mathrm{~mm}$ to $0.32 \mathrm{~mm}$. The clearance of $0.32 \mathrm{~mm}$ results in the worst in rotational feeling in the conventional model, which is referred to as level 0 . Increase of the clearance indicates increase of height error in $+\Delta$ direction. Furthermore, the clearance of $0.0 \mathrm{~mm}$ represents a situation in which the face gear is in contact with the pinion at two flanks at the same time. The result was confirmed through human rotational feeling

Fig. 25 shows ratings judged by user feeling on the handle clearance. The $\mathrm{Y}$ axis represents ratings of the rotational feeling and a large number suggests good rotational feeling. The $\mathrm{X}$ axis represents handle clearance. Table. 3 shows the different levels of rotational feeling. For mass production, a rotational feeling over level 3 is required.

The graph shows that the optimized model is better than the conventional model, thereby confirmed that the optimized model is robust against alignment error. The optimized model has a wide range over which the rotational feeling is good.

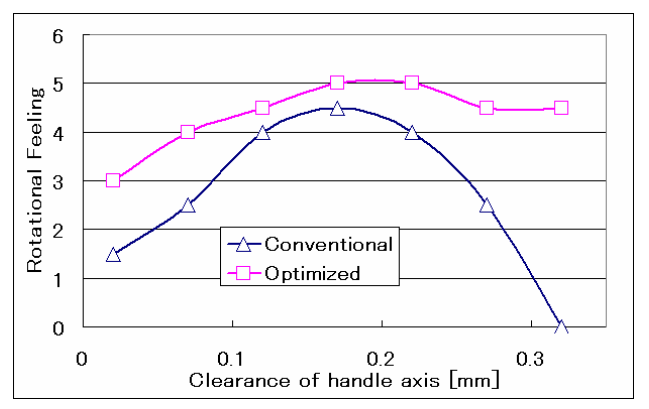

Table 3 Different levels of rotational feeling

\begin{tabular}{c||c}
\hline \hline Level 5 & Very good feeling \\
\hline Level 4 & Good feeling \\
\hline Level 3 & Normal feeling \\
\hline Level 2 & Slightly bad feeling \\
\hline Level 1 & Bad feeling \\
\hline Level 0 & Out of the question \\
\hline \hline
\end{tabular}

Fig 25 Effect of clearances of handle axis

\subsection{Result of simulation and TE measurement}

Fig. 26 (a) shows results by simulation on the handle clearance. Fig.26 (b) shows results by TE measurement system. The Y axis represents TE which was calculated by the same formula of Eq.(1), and the $\mathrm{Y}$ axis was reversed in relation to Fig.25. Therefore a small number indicates good rotational feeling.

Based on these results, the optimized model is better than the conventional model similar to the results based on human judgment. However the graph shows a range of good rotational feeling that is narrower than the result based on human judgment. Comparing Fig.26 (a) with Fig.26 (b), differences between the result based on the TE measurement and the result based on the simulation can be seen as absolute values, but the trends are almost the same.

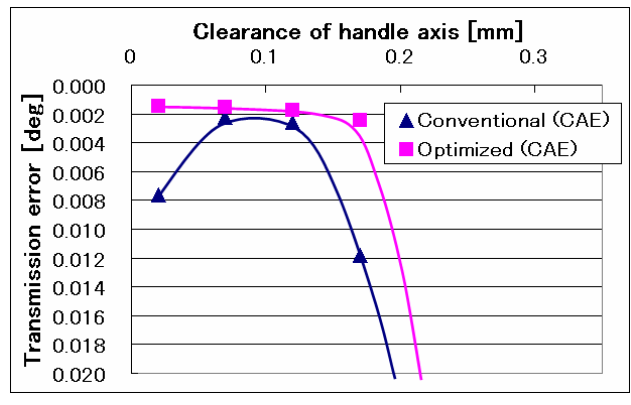

(a) Result based on simulation

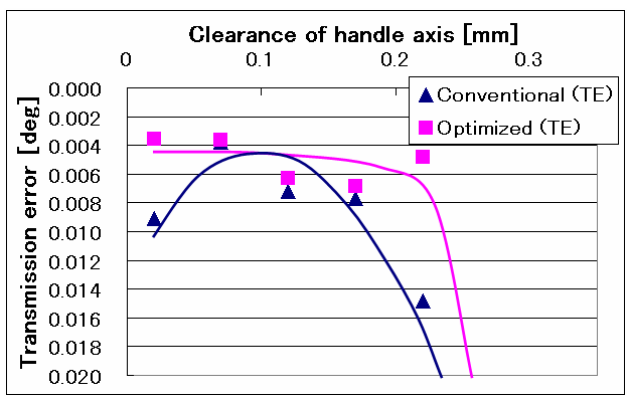

(b) Result based on TE measurement

Fig 26 Effect on handle axis clearances 


\section{Conclusions}

The results obtained from this research are as follows.

(1) The concrete procedure for deriving a path of contact based on a 3D tooth model and TE has been developed for face gears.

(2) An optimized model was established and manufactured. Based on the calculated TE, it was confirmed that the optimized model is robust against alignment error.

(3) A face gear with the optimized tooth flank was mounted on a spinning reel. Sensory evaluation based on the user feeling shows good performance with the optimized face gear.

\section{References}

[1] The Japan Society of Mechanical Engineers ed., JSME Mechanical Engineers' Handbook, Design $\beta 4$ Mechine Elements and Tribology, (2005), pp.82, Maruzen Ltd..

[2] Moriwaki, I. and Nishikura, Y., Computer Design System for Face Gears (Geometry of Face Gear with Offset), The JSMA Symposium on Motion and power Transmission 2007, No.07-15(2007-11), pp.171-173.

[3] Oshima, F. and Yoshino, H., Study on High Reduction Face Gears (1 st Report, Meshing Analysis), Transactions of the Japan Society of Mechanical Engineers, Series C, Vol. 72, No.720(2006), pp.336-342.

[4] Oshima, F. and Yoshino, H., Study on High Reduction Face Gears (3st Report, Proposal of Simplified Design Method), Transactions of the Japan Society of Mechanical Engineers, Series C, Vol. 73, No.732(2007), pp.201-206.

[5] Gunbara, H., Geometrical Design of Face Gear, Transactions of the Japan Society of Mechanical Engineers, Series C, Vol. 73, No.726(2007), pp.227-231.

[6] Oshima, F. and Yoshino, H. and Nagata E., A Study on High Reduction Face Gears (2nd Report, Cutting of Face Gear), Transactions of the Japan Society of Mechanical Engineers, Series C, Vol. 75, No.758(2009), pp.212-217.

[7] Oshima, F. and Yoshino, H., Contact Pattern and Running Performance of Face Gears with High Gear Ratio, The JSMA Symposium on Motion and power Transmission 2007, No.07-15(2007-11), pp.167-168.

[8] Tsuji, I., Gumbara, H. and Kawasaki, K. and Abe, Y., Development of High-Performance Face Gears (Machining and Performance Test), The 10th. Machine Design and Tribology Division Meeting in JSMA, No.10-10(2010-4), pp.105-108.

[9] Gunbara, H. and Kawasaki, K., Geometrical Design of Point-Contact Face Gear, Transactions of the Japan Society of Mechanical Engineers, Series C, Vol. 74, No.745(2008), pp.197-201. 